\title{
Comparative Analysis of Birth Weight in a Hospital Over a Decade: Low Birth Weight Still a Major Problem
}

\author{
Sachdeva $\mathbf{S}^{1}$, Nanda $\mathbf{S}^{2}$, Sachdeva $\mathbf{R}^{3}$ \\ ${ }^{1}$ Dr. Sandeep Sachdeva, MBBS, MD, DNB, DHA, \\ Department of Community Medicine, ${ }^{2} \mathrm{Dr}$. Smiti Nanda, \\ MBBS, MD, DGO, Professor, Department of Obstetrics \\ and Gynaecology, ${ }^{3}$ Dr. Ruchi Sachdeva, MBBS, DNB, \\ Department of Respiratory Medicine. All from Post \\ Graduate Institute of Medical Sciences, Rohtak, India.
}

\section{Introduction}

C onsiderable progress has been made in last three decades resulting in overall development which inter-alia paved way in reducing childhood morbidity and mortality across the globe, yet 8.8 million children die every year before their fifth birthday ${ }^{1}$. Nearly $49 \%(4.29$ million) of children death occurred in five countries-India, Nigeria, Democratic Republic of the Congo, Pakistan, and China ${ }^{2}$. Of the various putative causative factors, malnutrition still remains one of the major concerns, challenge and issue especially in developing countries to be overcome. Low birth weight (LBW) has been aptly identified as a major determinant of child health with immediate consequence during infancy and longterm impact on health outcomes in adult life. LBW is an outcome of either preterm birth or intrauterine growth restriction (IUGR) and is known to be an underlying factor in $60-80 \%$ of neonatal deaths.

According to the latest available international estimates $15 \%$ of all newborns were born with low birth weight $(<2500 \mathrm{~g})$ in the world and selected countries like China (2\%), Australia (7\%), Japan (8\%), UK (8\%), USA (8\%), Gambia (20\%), Nepal (21\%) \& Bangladesh accounted with $22 \%$ respectively. The picture with respect to LBW in India was $28 \%$ this decade (2011) with slight improvement from 33\% during last decade (2000), accounting a reduction of 5 units $^{3}$. With this background a cross-sectional comparative descriptive study was undertaken to determine magnitude of newborn weight in a government hospital and to explore association of low birth weight with selected variables.

\begin{abstract}
Introduction: The objective of this study was to compare the magnitude of birth weight and proportion of low birth weight in a hospital over a decade. Materials and Methods: A descriptive study was undertaken in a public funded hospital catering to rural and urban population of northern India. Pertinent information was collected for all intramural singleton births using structured proforma for a sample period in a calendar year. For comparison purpose birth data was extracted from log books for the corresponding period of previous decade also. Data management was done using MS excel sheet and analysis carried out by computing descriptive statistics using software statistical package. Results: The mean $(2568 \pm 596.7 \mathrm{gm}) \&$ median $(2600 \mathrm{gm})$ birthweight recorded for 2011 was low in-comparison to $2657 \pm 581.7 \mathrm{gm}(2750 \mathrm{gm})$ for 2001 . The prevalence of low birth weight (LBW) was $36.1 \%$ (2011) in comparison to $30.5 \%$ (2001) and the state of deterioration was found to be statistically significant $(p<0.001)$. Higher proportion of LBW birth was observed amongst un-booked ANC, pre-term, anemic mothers and whose residence was from outside the district of location of study institute $(<0.001)$. Statistically significant $(<0.001)$ and higher perinatal mortality was noticed in LBW neonates. Rising level of maternal education was protective against LBW. Mothers with their first pregnancy gave higher proportion of LBW births in comparison to mothers with higher gravida status $(<0.001)$.
\end{abstract}

Key words: Antenatal, Anemia, Education, Delivery, Nutrition, Poverty.

\section{Materials and Methods}

State of Haryana is one of the financially advance state of India (per capita income of Rupees 94,680 during 2010-11) with a population of 2.53 crores residing in 21 districts with life expectancy and literacy rate of 69

\section{How to cite this article?}

Sachdeva S, Nanda S, Sachdeva R. Comparative Analysis of Birth Weight in a Hospital Over a Decade: Low Birth Weight Still a Major Problem. J Nepal Paediatr Soc 2013;33(1):15-20. 
years and $76.6 \%$ respectively. Important latest statistics in comparison to country are: Birth rate, 21.8 (India: 21.8); Death rate, 6.5 (India: 7.1); Infant Mortality rate, 44 (India: 44); Sex ratio, 877 (India: 940); Child (0-6 years) sex ratio, 830 (India: 914); Maternal Mortality ratio, 153 (India: 212); Institutional deliveries, 77.3\% (India: 62\%); Complete immunization, 71.7\% (India: $61 \%$ ) and 3 ante natal check up, 75\% (India: 73.1\%) with total proportion of citizens $(30 \%)$ in country falling below national poverty line.

The study was conducted in one of the publically funded teaching institution of northern India which provides specialist's tertiary care services to patients largely belonging to lower/ middle socio-economic strata of the society with rural and urban background serving 4-5 adjoining districts. It caters to an avg. daily outpatient (OPD) attendance of 5000 patients and more than 80,000 annual admissions supported by 1750 inpatient beds. Birth weight of all new born was recorded using weighting scale immediately after birth upto onehour. All standard operating procedure of labor room were undertaken e.g. calibration of weighing instrument before recording weight of newborn, adequate lightening etc. to name a few.

The maternal and newborn variables included in the study were age, occupation \& education of mother, usual place of residence, booked/un-booked ante-natal (ANC) status, estimated period of gestation, gravida, hemoglobin, birth weight, sex and outcome (live/ mortality). Considering feasibility it was envisaged to collect pertinent information of all singleton intramural births occurring during randomly selected four months of the year 2011. Similarly log books of labor room were retrieved and reviewed for the corresponding timeframe of 2001 to record birth weight and other variables. Atleast one of the investigators was present during both the study time frame. During this period, weighing machine was replaced atleast four times because of maintenance issues but of the same company and make. The machine was placed at the same location/ site in the labor room during both the time frame.

Data collection was carried out by resident on duty after orientation training under the supervision of investigators using structured proforma after taking clearance from authority and verbal consent of mothers in a non-judgmental and confidential manner. The staff nurses involved in labor room activities was also given re-orientation training. All mothers were provided casebased advise regarding breast feeding, immunization, post natal care, family planning, nutrition, follow up etc. Detail information of all intramural births was then entered into MS excel spread sheet and analysis carried out using software statistical package (SPSS ver. 16). Some of the information was not available $(8.0 \%)$ and such case entries were excluded from final analysis. Standard definition as relevant to birth weight considered in the present study was LBW $(<2500 \mathrm{~g})$, Very LBW $(<1500 \mathrm{~g})$, Extremely LBW $(<1000 \mathrm{~g})$; Aneamia according to hemoglobin $(\mathrm{Hb})$ level as mild $(10-10.99 \mathrm{gm} / \mathrm{dl})$, moderate $(7-9.99 \mathrm{gm} / \mathrm{dl})$, severe (less than $7 \mathrm{gm} / \mathrm{dl})$ and no aneamia (atleast $11 \mathrm{gm} / \mathrm{dl}$ ).

\section{Results}

There were a total of 2812 \& 1577 births recorded for the sampled period during 2011 and 2001 . Majority (34.7\%) of mothers (2011) did not attend to school while majority $(37.9 \%)$ had atleast 9 -year of schooling during 2001 while age-structure \& gravida status of mothers for both periods was similar. Higher proportion of mother (72\%) was resident of district of location of study institution (2001) in comparison to 59\% (2011). Majority of women were home-maker, 90.2\% (2011) and 85.1\% in 2001 .

The mean (2568+596.7 gm) \& median (2600 gm) birth-weight recorded for 2011 was low in-comparison to $2657 \pm 581.7 \mathrm{gm} \& 2750 \mathrm{gm}$ as recorded for 2001 . The birth weight of male, female and live neonate was 2.61 $\mathrm{kg}, 2.50 \mathrm{~kg}$, and $2.61 \mathrm{~kg}$ respectively during 2011 . The prevalence of low birth weight (LBW) was $36.1 \%$ (2011) in comparison to $30.5 \%$ (2001) and this deterioration was found to be statistically significant $(p<0.001)$. Further analysis amongst LBW newborn showed that Very LBW constituted 22.8\% (2011) \& 14.4\% (2001) and Extremely LBW constituted $4.3 \%$ \& $4.4 \%$ for the corresponding period (Table-1).

Association of LBW with selective variables: Details are shown in Table-2. Rising level of education was protective against LBW. Majority of LBW occurred to mother in age group of 20-29 years followed by $30 /$ above and less than 19 years but this observation was statistically non-significant. Mothers with their first pregnancy gave birth to higher proportion of LBW births in comparison to higher gravida mothers in the recent year $[<0.001]$. For both time frame, higher proportion of LBW birth was observed amongst un-booked, pre-term mothers and whose residence was from outside the district of location of study institute $(<0.001)$. Statistically significant $(<0.001)$ and higher perinatal mortality was noticed in LBW neonates. Higher proportion of females were born with LBW during 2011 (<0.001). 
Table 1: Distribution of neonatal birth weight in the government hospital, Rohtak

\begin{tabular}{|c|c|c|c|}
\hline Item & 2001 & 2011 & Total \\
\hline \multicolumn{4}{|c|}{ Birth weight (kg.) } \\
\hline mean \pm S.D. & $2.65( \pm 0.58)$ & $2.56( \pm 0.59)$ & $2.59( \pm 0.59)$ \\
\hline Male & $2.69( \pm 0.61)$ & $2.61( \pm 0.58)$ & $2.64( \pm 0.59)$ \\
\hline Female & $2.61( \pm 0.53)$ & $2.50( \pm 0.60)$ & $2.54( \pm 0.58)$ \\
\hline Live & $2.71( \pm 0.52)$ & $2.62( \pm 0.54)$ & $2.65( \pm 0.53)$ \\
\hline Median & 2.75 & 2.60 & 2.70 \\
\hline \multicolumn{4}{|c|}{ Proportion (\%) of Low Birth Weight (LBW) } \\
\hline$\geq 2500 \mathrm{~g}$ & $69.5 \%$ & $63.9 \%$ & $65.8 \%$ \\
\hline$<2500 \mathrm{~g}(\mathrm{LBW})$ & $30.5 \%$ & $36.1 \%$ & $34.1 \%$ \\
\hline \multicolumn{4}{|c|}{ Distribution of birth weight amongst LBW neonates } \\
\hline$<1000 \mathrm{~g}$ & $04.4 \%$ & $04.3 \%$ & $04.4 \%$ \\
\hline $1000-1499 \mathrm{~g}$ & $10.0 \%$ & $18.5 \%$ & $15.8 \%$ \\
\hline $1500-1999 \mathrm{~g}$ & $19.6 \%$ & $23.6 \%$ & $22.3 \%$ \\
\hline $2000-2499 g$ & $66.0 \%$ & $53.6 \%$ & $57.4 \%$ \\
\hline
\end{tabular}

Table 2: Association of Low Birth Weight (LBW) according to selected variables

\begin{tabular}{|c|c|c|c|c|}
\hline \multirow[b]{2}{*}{ Item } & \multicolumn{2}{|c|}{$2001(\%)$} & \multicolumn{2}{|c|}{$2011(\%)$} \\
\hline & $\begin{array}{c}\text { LBW } \\
(<2.5 \mathrm{~kg})\end{array}$ & $\begin{array}{l}\text { NORMAL } \\
(\geq 2.5 \mathrm{~kg})\end{array}$ & $\begin{array}{c}\text { LBW } \\
(<2.5 \mathrm{~kg})\end{array}$ & $\begin{array}{l}\text { NORMAL } \\
(\geq 2.5 \mathrm{~kg})\end{array}$ \\
\hline \multicolumn{5}{|c|}{ Education of mother* } \\
\hline No schooling & 23.8 & 16.5 & 44.1 & 32.5 \\
\hline $1-8^{\text {th }}$ class & 25.8 & 20.7 & 22.5 & 22.8 \\
\hline $9^{\text {th }}$ class/above & 50.3 & 62.8 & 33.4 & 44.6 \\
\hline \multicolumn{5}{|c|}{ Age of mother (years) } \\
\hline Upto 19 & 6.5 & 4.8 & 3.5 & 2.8 \\
\hline $20-29$ & 82.2 & 85.9 & 87.9 & 89.1 \\
\hline 30 or above & 11.2 & 9.3 & 8.6 & 8.1 \\
\hline \multicolumn{5}{|c|}{ Residence* } \\
\hline Within district & 69.0 & 77.9 & 53.2 & 62.4 \\
\hline Outside district & 31.0 & 22.1 & 46.8 & 37.6 \\
\hline \multicolumn{5}{|c|}{ ANC status* } \\
\hline Un-booked & 30.55 & 22.2 & 68.8 & 51.6 \\
\hline Booked & 69.5 & 77.8 & 31.2 & 48.4 \\
\hline \multicolumn{5}{|c|}{ Gravida } \\
\hline First & 43.0 & 40.9 & 45.3 & 39.3 \\
\hline Second & 28.2 & 29.6 & 27.5 & 33.6 \\
\hline Third or more & 28.8 & 29.6 & 27.1 & 27.0 \\
\hline \multicolumn{5}{|c|}{ Period of gestation* } \\
\hline 28- 36 weeks & 46.7 & 7.6 & 50.0 & 8.2 \\
\hline 37 weeks/more & 53.3 & 92.4 & 50.0 & 91.8 \\
\hline \multicolumn{5}{|c|}{ h/o Abortion } \\
\hline None & 85.6 & 86.9 & 83.6 & 82.9 \\
\hline Present & 14.4 & 13.1 & 16.4 & 17.1 \\
\hline \multicolumn{5}{|c|}{ Maternal aneamia* } \\
\hline Severe & 16.2 & 8.8 & 6.7 & 3.1 \\
\hline Moderate & 55.7 & 54.8 & 55.0 & 56.1 \\
\hline Mild & 22.7 & 25.2 & 30.1 & 33.3 \\
\hline No aneamia & 5.4 & 11.2 & 8.2 & 7.5 \\
\hline
\end{tabular}

${ }^{*} \mathrm{p}<0.001$ 


\section{Neonatal institutional birth weight in kilogram (mean) over a decade, Rohtak}

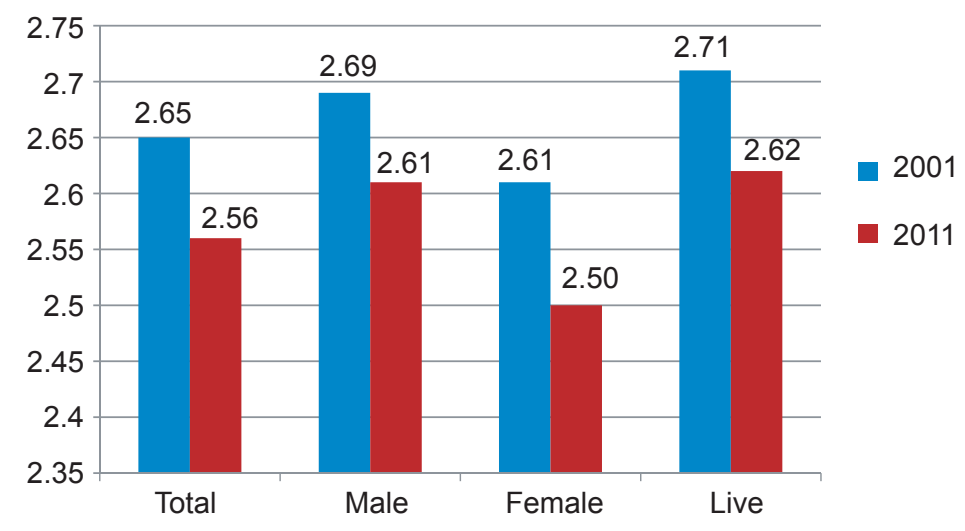

Proportion of low birth weight (LBW) amongst institutional birth, Rohtak

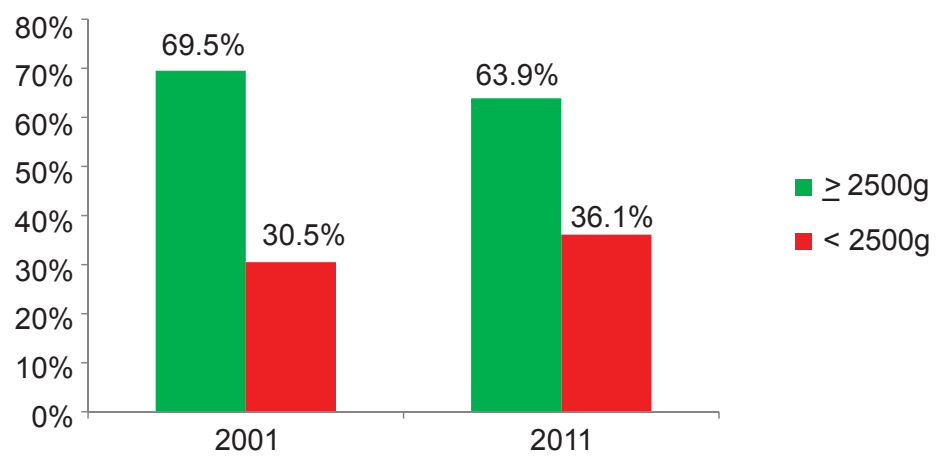

\section{Discussion}

A descriptive study was undertaken to document birth weight over a decade in a government hospital in the state of Haryana. The study revealed that median birth weight in $2011(2.6 \mathrm{~kg})$ was lower than $2001(2.75$ $\mathrm{kg}$ ) with proportion of LBW as $36.1 \%$ (2011) and $30.5 \%$ (2001). India, the largest democracy \& second most populous country in the world is striving strongly on all fronts of human development especially economic value yet lagging on social issues. Over the years there has been intense promotion for institutional deliveries in the country with concomitant increased program funding, infrastructure development, easy access to communication and free transport facilities for pregnant and poor patients. However, nation-wide data on birth is still not available since most of these occur at home i.e. $52.3 \%(61.3 \% \text { in rural and } 29 \% \text { in urban areas })^{4}$ with latest figure of $60 \%$ (Sample Registration System, 2010).

Inspite of certain inherent limitations as hospital usually attracts high risk mothers with nongeneralizability of study findings still it reflects a grim situation with respect to neonatal birth weight. Another trend being observed in this region especially in the light of large scale migration of labor due to infrastructure and agriculture development with issues like poverty, social security, manual physical labor and poor nutrition with profound influence on birth weight could also add on to listed limitations.

Data based on nationally representative Demographic Health Survey (DHS) of 1993 \& 1999 in India after adjustment of birth-size for heaping, LBW was reported to the tune of $31.7 \%$ and $30.4 \%$ respectively ${ }^{5}$. A community based study in rural areas of West Bengal, urban re-settlement of Delhi and Pune documented the magnitude of LBW as $31.3 \%, 39.1 \%$ and $29 \%$ respectively $^{6-8}$. National Neonatal-Perinatal Database (NNPD) from secondary \& tertiary care network $(n=15)$ reported LBW as $31.3 \%(2002-03)^{9}$ while isolated Indian hospital based studies at Orissa, Shimla, Bhilai and Amritsar, reported LBW as $39.8 \%, 27.8 \%, 23 \%$ and $16.3 \%$, respectively ${ }^{10,11,12,13}$.

The multi-factorial complex inter-linked factors leading to LBW could be grouped into biological (maternal, placental, fetal etc), social-economic determinantspoverty, demography, education, cultural \& nutritional 
practices, infections (e.g. malaria etc), health system (availability, access, quality \& compliance), tobacco exposure, or environmental related issues ${ }^{14,15,16,17,18,19,20}$. Much has been deliberated \& documented on enlisted parameters. In the back-drop of various factors enlisted and variables examined in present study, authors would broaden the discussion to cover environmental issues in particular.

Carbon monoxide $(\mathrm{CO})$ in particular and nicotine are regarded as the agents most likely to be responsible for detrimental effects on intrauterine growth ${ }^{21}$. CO results from incomplete combustion of bio-fuels (wood, dung, and fiber residues) as well as fossil fuels such as coal and gas that is used for cooking and heating biomass and also tobacco. Studies have shown that exposure to biofuels is associated with carboxy-heamoglobin $(\mathrm{COHb})$ levels of $2.5-13 \% \%^{22,23}$. This compound does not readily give up oxygen to peripheral organs and tissue including foetus thus leading to growth restriction. A study carried out Guatemala confirmed that children born to mothers habitually cooking on open fires had the lowest mean birth weight of $2,819 \mathrm{~g}$; those using a chimney stove had an intermediate mean of $2,863 \mathrm{~g}$; and those using the cleanest fuels (electricity or gas) had the highest mean of $2,948 \mathrm{~g}(p<0.0001)$. The proportion of low birth weights in these three groups was 19.9\% (open fire), $16.8 \%$ (chimney stove), and $16.0 \%$ (electricity/gas) ${ }^{24}$. A study carried out in south India, reported that exposure to bio-mass fuel was associated with an adjusted $49 \%$ increased risk of $\mathrm{LBW}^{25}$.

It may not be un-reasonable to interpret that biofuels used by Indian women for cooking or heating may be one of the likely causes of LBW in addition to studied co-variables. Considering environmental issues, nearly $65.4 \%$ of rural $\& 26.5 \%$ of urban households in India used fire wood for cooking. In Haryana, nearly $61.8 \%$ [76.6\% (rural) and 22\% (urban)] used fuel other than (LPG, electricity, or kerosene) suggesting dung/ crop/fiber residue etc. while $11 \%$ of household used woods for cooking. On the health front, more than $50 \%$ mothers are anaemic while mothers who consumed IFA supplements were only $29.0 \%$ (urban, $31.7 \%-28.1 \%$, rural $)^{26}$. Similarly, adult prevalence of tobacco use at national level among males is $48 \%$ and that among females is $20 \%$ while prevalence of smoking among males is $24 \%$ and $3 \%$ among females including $1 \%$ each of pregnant and breastfeeding women (NFHS-3, Haryana $)^{27}$. Similarly higher proportion of rural $(58 \%)$ than urban $(39 \%)$ adults were exposed to second hand smoke in their homes.

Considering background discussion it may not be surprising to visualize the interface that substantial gain on newborn birth weight will be achieved in conjunction with development of related sectors (e.g. energy/ tobacco control/poverty alleviation), tuberculosis/ malaria control, modification of cultural practices, improving health compliance and time-frame needed to do so etc. India, accounts for one of the highest magnitude of LBW newborn, a surrogate indicator for prevailing malnutrition \& inequity in the society leading to inter-generational effect especially among women. Directly and/or in-directly country is bearing \& draining huge resources when the consequences are translated from the perspective of health, loss of productivity and psycho-social cost into financial terms. Maternal and child health is considered as one of the major thrust areas in country with many concentrated interventions underway by government of India still a lot needs to be done in this direction.

\section{Conclusion}

To conclude, with a pinch of salt, we have faltered in achieving health \& family welfare goals as envisaged in Health-for-All (e.g. to bring down LBW to $10 \%$ by the year 2000), National Population Policy (2000) and National Health Policy (2002) etc. High aspirations, hopes \& targets, which are though necessary for guiding path \& raising moral of health team, have resulted in modest progress only. But to reiterate, integrated strategies, actions \& will is the hallmark required to bring down the scale of malnutrition and improvement in related sectors so as to achieve at least some of the Millennium Development Goals (MDG, 2015) or else it would still remain just one of the many fancy dreams and charter of wish-lists to be achieved by, to be realistically saying, at least not before year 2030 .

Acknowledgements: We would like to thank the Vice Chancellor, Director, Staff from the departments of Obstetrics and Gynaecology, Paediatrics and Community Medicine, PGIMS, Rohtak.

Funding: None

Conflict of Interest: Nil

Permission from IRB: Yes

\section{References}

1. You D, Wardlaw $T$, Salama $P$, Jones $G$. Levels and trends in under-5 mortality, 1990-2008. Lancet 2010;375:100-3.

2. Black RE, Cousens S, Johnson HL, Lawn JE, Rudan I, Bassani DG, et al. Global, regional, and national causes of child mortality in 2008: a systematic analysis. Lancet 2010; 375(9730):1969-87.

3. State of World's Children-2009. UNICEF: New York; Dec 2008.

4. District Level Household and Facility Survey (DLHS-3), 2007-08: India. Mumbai: IIPS; 2010. 
5. Blanc AK, Wardlaw T. Monitoring low birth weight: an evaluation of international estimates and an updated estimation procedure. Bull World Health Organ 2005; 83:178-85.

6. Biswas R, Dasgupta A, Sinha RN, Chaudhuri RN. An epidemiological study of Low Birth Weight Newborns in the District of Puruliya, West Bengal. Ind J Public Health 2008;52:65-71.

7. Hirve SS, Ganatra BR. Determinants of low birth weight: a community based prospective cohort study. Ind Pediatrics 1994;31:1221-5.

8. Chhabra P, Sharma AK, Grover VL, Aggarwal OP. Prevalence of low birth weight and its determinants in an urban resettlement area of Delhi. Asia Pac J Public Health 2004;16:95-8.

9. National Neonatal-Perinatal Database. Report: 2002-03. New Delhi: AlIMS; 2005.

10. Tripathy R, Parida SN, Tripathy SN, Devi PS, Das RN, Swain A. Physical status of newborns and neonatal outcome. Ind J Pediatrics 2002;69:104145 .

11. Kaur D, Kaur AP, Rashmi. Changing trends in birth weight. J Obstet Gynecol India 2002;52:32-6.

12. Kaushik S, Grover N, Parmer VR, Grover PS, Kaushik R. Neonatal morbidity in a hospital at Shimla. Ind J Pediatrics 1999;66:374-76.

13. Misra M, Mishra S, Sharadamma. Epidemiology of low birth weight in an industrial area in India. $J$ Trop Pediatrics 1995;41:374-76.

14. Han Z, Mulla S, Beyene J, Liao G, McDonald SD et al. Maternal underweight and the risk of preterm birth and low birth weight: a systematic review and meta-analyses. Int J Epidemiol 2011;40:65-101.

15. Muthayya S. Maternal nutrition \& low birth weight - what is really important? Ind J Med Res 2009;130:600-08.

16. Low birth weight: country, regional and global estimates. UNICEF and WHO, New York and Geneva; 2004.
17. Sachdev HPS. Low birth weight in south Asia. Int $J$ Diab Dev Countries 2001;21:13-31.

18. Claeson M, Bos ER, Mawji T, Pathmanathan I. Reducing child mortality in India in the new millennium. Bull. World Health Organ 2000;78:119299.

19. Singh N, Shukla MM, Sharma VP. Epidemiology of malaria in pregnancy in central India. Bull World Health Organ 1999;77:567-72

20. Kramer MS. Determinants of low birth weight: methodological assessment and meta-analysis. Bull World Health Organ 1987;65:663-73.

21. Longo LD. The biological effects of carbon monoxide on the pregnant woman, fetus, and newborn infant. Am J Obstet Gynecol 1997;129:69-103.

22. Dary O, Pineda O, Belizan J. Carbon monoxide in dwellings in poor rural areas of Guatemala. Bull Environ Contam Toxicol 1981;26:24-30.

23. Behera D, Dash S, Malik S. Blood carboxyhaemoglobin levels following acute exposure to smoke of biomass fuel. Ind J Med Res 1988;88:522-42.

24. Boy E, Bruce N, Delgado H. Birth Weight and Exposure to Kitchen Wood Smoke during Pregnancy in Rural Guatemala. Environ Health Persp 2002;110:109-14.

25. Tielsch JM, Katz J, Thulasiraj RD, Coles CL, Sheeladevi S, Yanik EL, et al. Exposure to indoor biomass fuel and tobacco smoke and risk of adverse reproductive outcomes, mortality, respiratory morbidity and growth among newborn infants in south India. Int J Epidemiol 2009;38:1351-63.

26. International Institute for Population Sciences (IIPS), 2010. District Level Household and Facility Survey (DLHS-3), 2007-08:India. Haryana: Mumbai: IIPS.

27. Global adult tobacco survey. GATS India: 20092010. Mumbai: IIPS; 2010. 